\title{
The Cleanness and Purity of Muslim woman's soul and heart or home traditions
}

\author{
Islomova Zilola Rustamovna \\ University of Law, Uzbekistan Teacher of English, Department of languages
}

\begin{abstract}
Since ancient times females usually had strong belief and trust to cleanness. Their eyes meant to see beauty and challenges of the Life. For example, green-eyed females are thought to be blessed by heaven with the purity of Ocean and Sky. The greenness of their eyes symbolizes green life, beauty of ocean underwater that is green. For these reason, the newborn girl is given a symbolic item that saves her during her life. They told it Nazar. The symbolic item was hang into their clothes or cap that she wears. They believe that this symbolic item keeps her from unhappy conditions during each steps of her life.

In different part of the world people have their symbolic items that they consider holy. Uzbek females and girls tend to keep the cleanness and purity of their heart and soul by various traditions.
\end{abstract}

Keywords: writing; eyes; blue eyes; ocean; symbols

\section{The Cleanness and Purity of Muslim woman's soul and heart and home traditions}

Since ancient times females usually had strong belief and trust to cleanness. Their eyes meant to see beauty and challenges of the Life. For example, green-eyed females are thought to be blessed by heaven with the purity of Ocean and Sky. The greenness of their eyes symbolizes green life, beauty of ocean underwater that is green. For these reason, the newborn girl is given a symbolic item that saves her during her life. They told it Nazar. The symbolic item was hang into their clothes or cap that she wears. They believe that this symbolic item keeps her from unhappy conditions during each steps of her life.

In different part of the world people, have their symbolic items that they consider holy. However, Uzbek females and girls tend to keep the cleanness and purity of their heart and soul by various assumptions. Interestingly some of the families hang items like these into the earrings of the newborn baby.

Sometimes, one could see items within the blue eyes on the walls of the kitchens and shops. According to their belief and trust, these eyes keep them from hard and bad eyes. These is Muslim belief and one of the customs that is inherited from generation to generation. 


\section{4th International Conference On}

\section{Modern Approaches in SCIENCE, TECHNOLOGY \& ENGINEERING
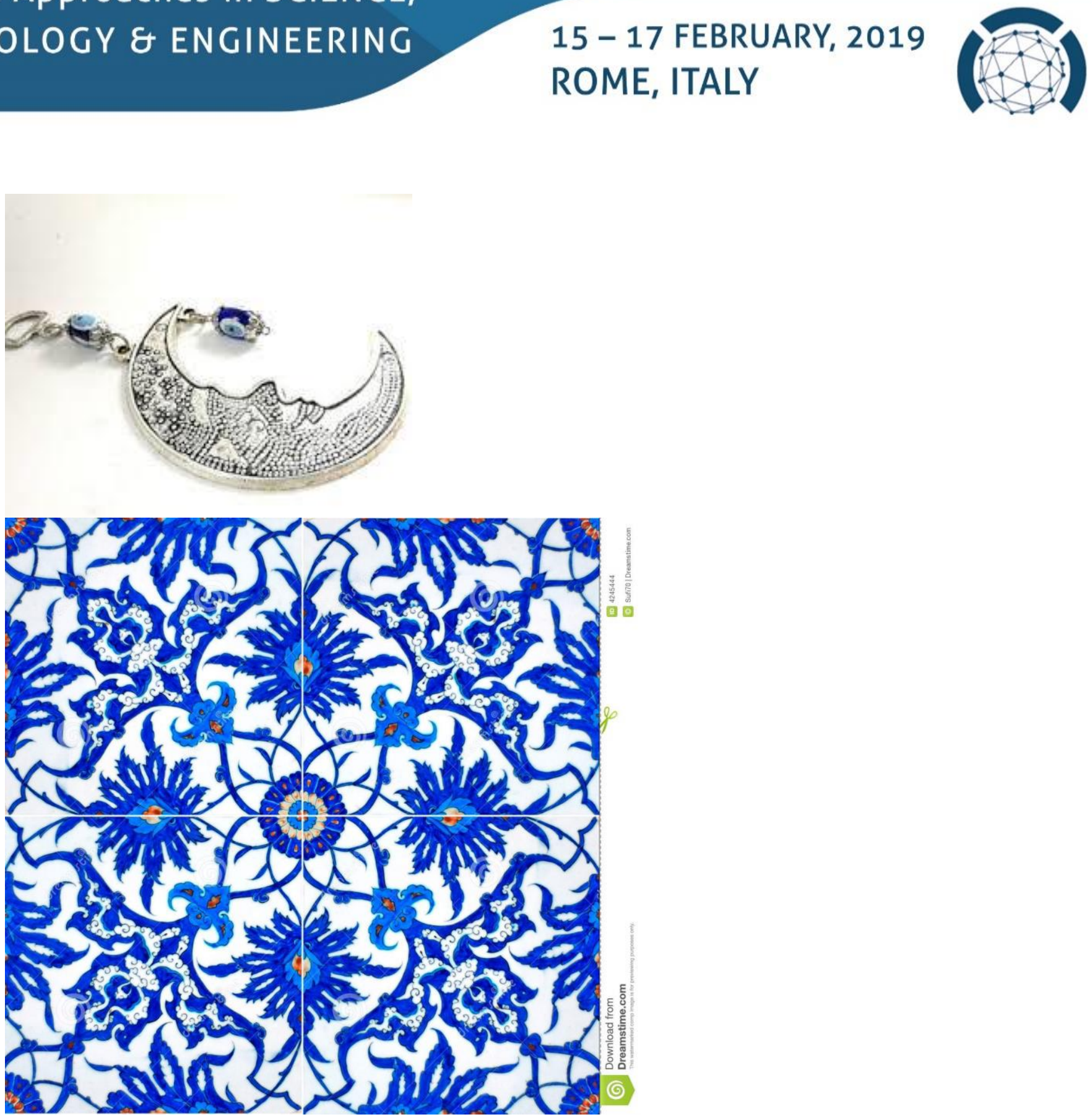

Some of the Uzbek females trust only to the purity of Ocean, it would be correct to say that to purity of the Pacific Ocean. They think that that there is nothing clean on the in the Earth. The only clean place is underwater life in the Pacific Ocean. Because, some of the human being is blessed to live in the ocean during entire his life. They explore, search and find new items every day. So, they do not pollute water the as we do in everyday life on the earth.

The profession of oceanology is considered to be the holiest job that human being is blessed with. Because, people who are engaged in these jobs will be able to discover the lifelong beauty and nonstop discoveries of the underwater life.

For these reasons, some of the Muslim woman keep the pictures of the underwater life, pictures of ocean creatures, shines and sun falls over the pacific oceans during their lives.

But A nazar (from Arabic نظر Arabic pronunciation: [nað`ar], word deriving from Arabic, meaning sight, surveillance, attention, and other related concepts) is an eyeshaped amulet believed to protect against the eyes of others. Albanian, Urdu, Pashtun, Bengali, Kurdish, Persian, and other languages have 


\section{4th International Conference On}

\section{Modern Approaches in SCIENCE, \\ TECHNOLOGY \& ENGINEERING

borrowed the term as well. In Uzbek it is known by the name nazar munchogi (the latter word being a derivative of "bead", and the former borrowed from Arabic) and historically as mâvi boncuk or Old Turkic: gökçe munçuk, both meaning In Persian and Afghan folklore, it is

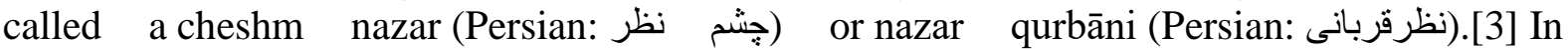
Uzbekistan it is called " ko'z munchoq"

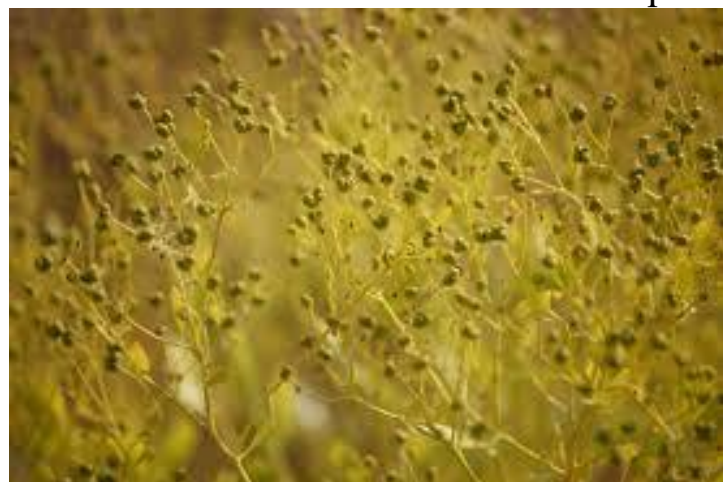

In muslim cultures, it is believed that if a person is complimented a lot, the wrong eye will cause them to be sick the next day unless a phrase such as "With the will of God" ("MashAllah" in Arabic) is said. In South Asia, when a mother observes that her child is being excessively ill, it is common for them to attempt to neutralize the effects of the eye by "holding isiriq in one hand and circling the child's head a few times, then burning the isiriq."

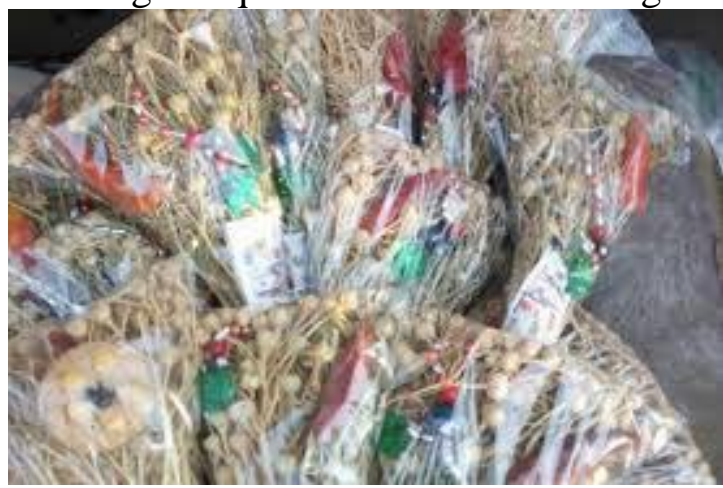

Uzbek people have not only clean soul and hearts but they are very hospitable. The Uzbek celebrations are more interesting. One of them is Navruz, the start of new lives and New Years, days, New opportunities. During this day one could see the beauty of Uzbek female when they wear their traditions dresses and embroideries.

In Asia Christmas is considered to be the European and foreign holyday. But most of the Muslim girls who study English and foreign languages understand its importance and try to make new year of their towns celebrations as beautiful as it is in EU and English speaking countries. By the way in Uzbekistan people have the season it is called the season of harvest and preparation for winter. Especially, in the months of October most of the farmers harvest their crops and celebrate the date when their achieve their aimed results. It reminds Thank Giving Day of English speaking countries. Some of the aristocrats even cook Turkey in New Year days, which reminds Thanksgiving, Christmas and Easter in UK and USA. The fireplace in the heart of the home which are located in outskirts of the towns remind the real British homes. 


\section{4th International Conference On}

Modern Approaches in SCIENCE,

TECHNOLOGY \& ENGINEERING

\section{5 - 17 FEBRUARY, 2019 ROME, ITALY}

1. https://www.google.com/search?q=isiriq+rasmlari\&rlz=1C1GGRV_enUZ776UZ776\&tbm=is ch\&source=iu\&ictx=1\&fir=41_yd7Lw0OVyPM\%253A\%252CGRHopXugmS8SOM\%252C

_\&usg=AI4_-

kTuByaVakLIXAybxbU2sTh19UHB5g\&sa=X\&ved=2ahUKEwjC4qOaurjfAhURposKHe0 WA5gQ9QEwBHoECAYQDA\#imgrc=41_yd7Lw0OVyPM:

2. The holy concept 7 in various culture, Articles, The journal of socio economic issues. The national polytechnic university, 2012

3. The socio linguistic aspects of concept labour in English and Uzbek languages Articles, The journal of socio economic issues. The national polytechnic university, 2012

4. The concept work in various cultures and the importance of work in English, Russian and Uzbek cultures. Articles, The journal of socio economic issues. The national polytechnic university, 2012 